\title{
ESTUDO GRAVIMÉTRICO DO MACIÇO ALCALINO DE POÇOS DE CALDAS
}

\author{
GABRIELA DE BRITTO SLAVEC ${ }^{1}$, MARTA SILVIA MARIA MANTOVANI² \& \\ WLADIMIR SHUKOWSKY ${ }^{3}$
}

\begin{abstract}
GEOPHYSICAL STUDYOF THE POÇOS DE CALDAS ALKALINE COMPLEX A gravimetric survey was held at the Poços de Caldas alkaline massif located at the border between Minas Gerais and Sao Paulo States, southeastern Brazil. Combining the existent and the new established gravity stations for this work, a total of 783 data points were available. Four profiles crossing the region were analyzed to produce a $2.5 \mathrm{D}$ geometry model; the obtained result was compared to a 3D independent model. The best fit model indicate a volume of $7,220 \mathrm{~km}^{3}$ for the massif, which maintains the alkaline intrusion as second of largest size in the world.
\end{abstract}

Keywords: Alkalines Rocks, Poços de Caldas Massif, Gravity Survey.

Resumo Foi realizado um levantamento gravimétrico na área ocupada pelo Maciço alcalino de Poços de Caldas, localizado na divisa entre os Estados de São Paulo e de Minas Gerais, SE do Brasil. Um total de 783 estações gravimétricas, entre já existentes e novas implantadas para o propósito, foi utilizado no presente trabalho. Foram modelados com geometria 2,5 D quatro perfis que cruzam a região. e os resultados obtidos foram comparados com um modelo com geometria $3 \mathrm{D}$, independente. O melhor ajuste sugere para o maciço um volume de $7.220 \mathrm{~km}^{3}$, valor este que o classifica como segundo maior corpo deste tipo no mundo.

Palavras-chave: rochas alcalinas, maciços de Poços de Caldas, gravimetria.

INTRODUÇ̃̃O Localizado na região SE do Brasil, na divisa dos Estados de São Paulo e Minas Gerais, o Maciço Alcalino de Poços de Caldas ocupa uma área na superfície aproximadamente circular de cerca de $800 \mathrm{~km}^{2}$ (Ulbrich 1984), sendo um dos maiores maciços alcalinos conhecidos no mundo (Fig. I). Trabalhos de geocronologia apresentam idades $\mathrm{K}$-Ar para o maciço que variam entre $87 \mathrm{Ma}$, para a etapa inicial de domeamento, e $53 \mathrm{Ma}$, para as últimas manifestações, como diques de fonolitos em nefelina sienitos.

Para o presente trabalho foi realizado um levantamento gravimétrico de semi-detalhe realizado na região, que caracteriza bastante bem a área de estudo. A partir dos resultados, estabeleceram-se quatro perfis, que foram modelados em $2.5 \mathrm{D}$ e comparados com modelos $3 \mathrm{D}$, utilizando determinações das densidades de rochas coletadas na região, fundamentando uma discussão acerca do modelo gravimétrico mais favorável para o maciço em profundidade. Os resultados deste trabalho indicam, para o Maciço de Poços de Caldas, um volume máximo provável de $7.220 \mathrm{~km}^{3}$, o que implica no deslocamento de grandes volumes de rocha encaixante.

GEOLOGIA DA REGIÃO Apesar de ocuparem áreas bastante reduzidas na escala mundial, as rochas alcalinas têm sido intensamente pesquisadas face ao interesse que apresentam por seus aspectos econômicos, petrológicos e geodinâmicos (Sørensen 1974). O Maciço Alcalino de Poços de Caldas apresentase num alto topográfico, com cotas acima dos $1.400 \mathrm{~m}$, com conjuntos de elevações sustentadas por fonolitos marginais, tendo sido interpretado por Ellert, já em 1959, como expressão de um dique anelar. Por dentro dos anéis topográficos ocorre uma depressão, substituída mais para o centro do maciço por paisagens de morros e vales.

O mapa geológico da figura 2, elaborado por Ulbrich (1992) mostra a distribuição dos tipos litológicos na região estudada. O Maciço Alcalino de Poços de Caldas, sobre o qual estão localizados os depósitos do distrito, é, então, constituído por rochas nefelínicas, predominando particularmente os tinguaítos. A idade das rochas encontradas na intrusão varia de 53 a $87 \mathrm{Ma}$ (Ulbrich 1992).

No interior do maciço ocorrem ainda rochas sedimentares argilo-arenosas, e materiais vulcânicos como tufos, brechas e lavas alcalinas. O conjunto representa um complexo sub-vulcânico com restos de material da cobertura vulcânica original, ainda preservada (Parisi 1988).

O contato das rochas alcalinas de Poços de Caldas com o embasamento nãoé, em geral, direto. Identifica-se, em muitos casos, uma "zona de contato", na qual as rochas do embasamento se encontram permeadas por pequenos corpos de fonolitos, por vezes de tamanhos mapeáveis. Uma avaliação sistemática torna-se difícil, já que estas zonas aparecem geralmente como conjuntos de blocos rolados, onde se misturam rochas do embasamento com fonolitos e, muito mais raramente, também com nefelina sienitos.

Observações não tão recentes mostram que muitas das erupções de vulcões ativos são precedidas por "domeamentos" locais ou regionais; em outros casos, ocorre um soerguimento prévio da área (Ulbrich 1992). O "problema do espaço", se liga à necessidade de deslocar volumes consideráveis de rochas encaixantes, ativas ou passivamente, para acomodar as quantidades equivalentes do magma intrusivo. A análise geofísica complementa a interpretação geológica, fornecendo uma melhor compreensão dos processos de formação e domeamento na região de Poços de Caldas. 


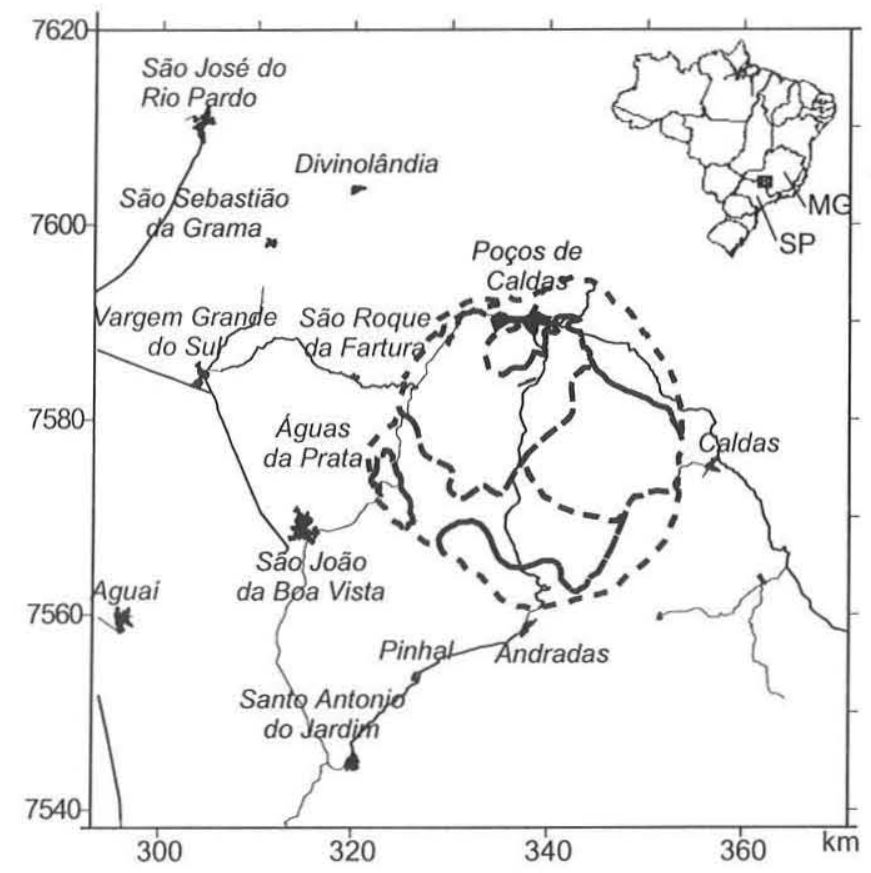

Figura I - localização da região de estudo no Brasil. Limite geológico do Maciço alcalino de Poços de Caldas tracejado e'm cinza.
MÉTODOS DE TRABALHO As medidas de aceleração de gravidade g na região de Poços de Caldas foram efetuadas com um gravímetro Lacoste \& Romberg, modelo G, com realimentação eletrostática analógica e precisão de $0,04 \mathrm{mGal}$. Todas as medidas foram referidas à rede gravimétrica fundamental através da estação gravimétrica de Poços de Caldas (EG-504), sendo cada medida acompanhada de um erro experimental, propagado para o valor de g. A distância relativa entre as estações varia de 500 a $1000 \mathrm{~m}$, sendo que o espaçamento entre duas medidas aumenta com a distância da borda do maciço para a região externa. No presente trabalho foram utilizadas 783 estações gravimétricas distribuídas por toda a área de estudo.

Paralelamente ao levantamento gravimétrico foram realizadas medidas de altimetria, pelo método de barometria controlada, através do registro contínuo em uma base fixa. As medidas foram referidas à Rede de Nivelamento de $1^{\text {a }}$ ordem do IBGE. O erro máximo estimado para essa metodologia é da ordem de $1,5 \mathrm{~m}$ no valor da altitude, correspondendo a menos de $0,2 \mathrm{mGal}$ quando propagado para o valor da aceleração da gravidade $g$ medido. Como a região apresenta uma topografia acidentada e desníveis notáveis, os dados altimétricos foram utilizados em conjunto com mapas topográficos, para efetuar a correção de terreno, obtendo, assim, a anomalia Bouguer completa.

A redução dos dados levantados foi feita parcialmente em campo, de forma a otimizar a distribuição dos pontos de medidas. A redução dos dados e análise dos resultados utilizou software específico para a finalidade (GRAVMAG), disponível junto ao
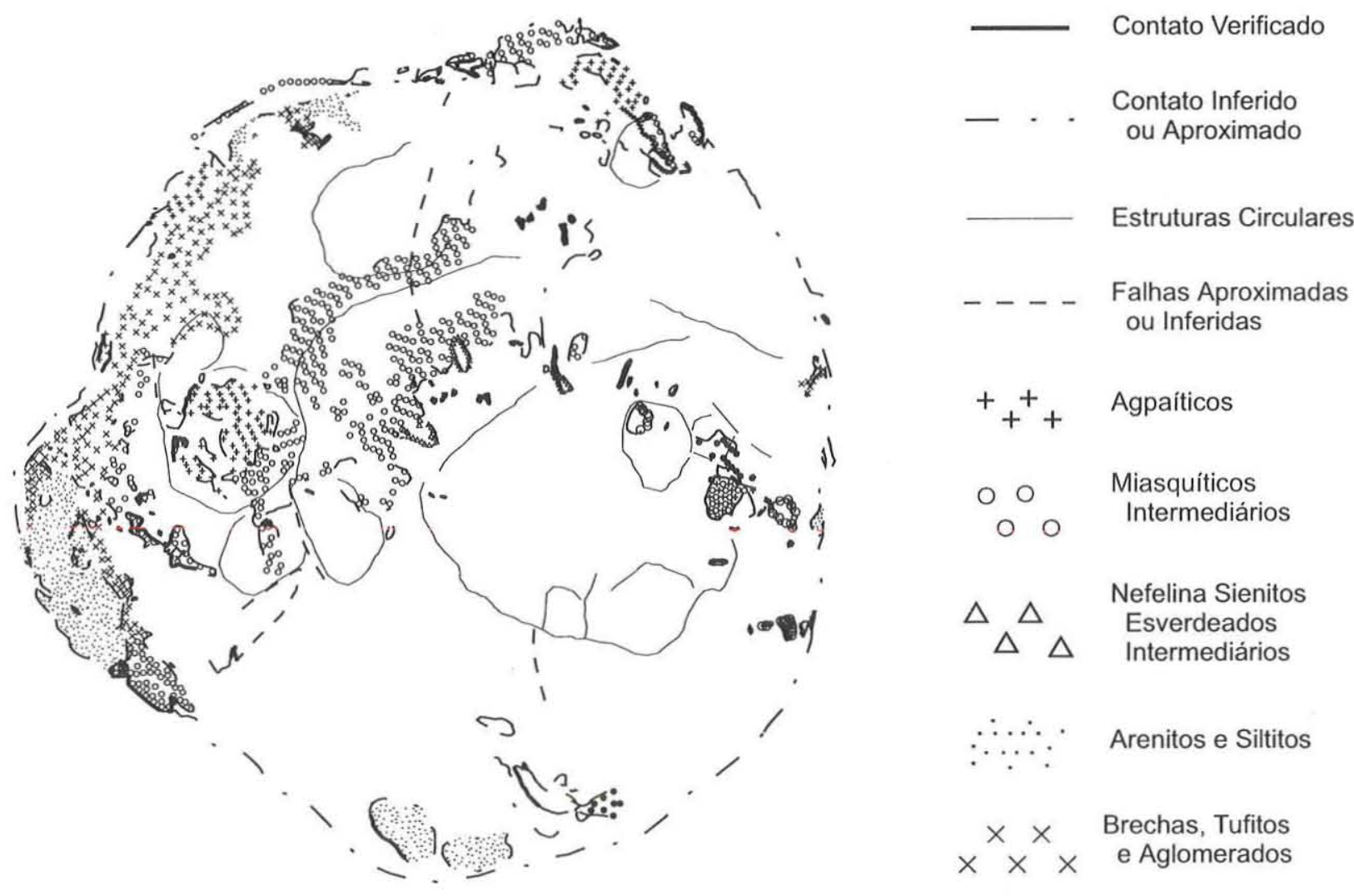

Figura 2 - Mapa geológico da região do Maciço Alcalino de Poços de Caldas (Ulbrich \& Ulbrich 1992) 
Departamento de Geofísica do IAG/USP, o que permitiu a análise de perfis com geometria $2.5 \mathrm{D}$ e a comparação desses resultados com modelos 3D efetuados com a utilização do algoritmo de Murthy \& Swamy (1995).

A coleta de amostras na região do Complexo Alcalino de Poços de Caldas permitiu a determinação das densidades, de acordo com o princípio de Arquimedes, das diferentes litologias para fins de modelagem da estrutura geológica do Complexo. Considerandose os resultados obtidos, a litologia de cada amostra coletada, a informação geológica disponível e as observações sobre os sistemas de lineamentos e falhas no interior do Maciço, o distrito foi dividido em seis grupos (A,B, C, D, E e F) de diferentes densidades (Figs. 3 e 6). A Tabela 1 apresenta os tipos litológicos e as densidades médias consideradas para a modelagem dos perfis.

Araújo (1978), ao analisar o fluxo térmico na região de Poços de Caldas, define diferentes áreas no interior do maciço com valores de gradiente de temperatura distintos, reforçando a divisão dos grupos de diferentes densidades utilizada neste trabalho.

$\mathrm{O}$ grupo $\mathrm{A}$ corresponde à região onde há maior ocorrência de alteração hidrotermal no distrito, com densidade média de $2,50 \mathrm{~g} /$ $\mathrm{cm}^{3}$, enquanto que o grupo B apresenta amostras com densidades mais elevadas, da ordem de $2,54 \mathrm{~g} / \mathrm{cm}^{3}$. O grupo $\mathrm{C}$ apresenta densidades bastante homogêneas, em torno de $2,47 \mathrm{~g} / \mathrm{cm}^{3}$. O grupo D aparece dividido em duas regiões, a NE e SE do Maciço, e foi definido como uma região de contato entre o embasamento e o corpo alcalino, já que diversas amostras apresentaram densidades acima dos valores encontrados no interior do Maciço.

Para representar o campo gravimétrico regional anômalo da região do maciço, foi utilizada uma superfície polinomial de grau 2 , obtida por Ajuste Polinomial Robusto, gerando-se o mapa da figura 3. Nesta mesma figura são apresentados os perfis utilizados para a modelagem da estrutura com geometria 2,5 D.

A seleção dos perfis utilizados na modelagem foi feita segundo critérios Geológicos, comportamento da anomalia Bouguer completa e localização das amostras in situ. A modelagem 2,5D, utilizou os quatro perfis que atravessam a região central do Maciço, considerando-se a presença de uma maior densidade de estações gravimétricals.

A modelagem dos perfis utilizou o método interativo, construindo-se o modelo a partir da comparação das curvas teórica e observada, ajustando-se o campo gravitacional observado e obtendo-se um modelo com geometria 2,5D. Para tal, foram considerados os dados da topografia e o valor de $2,66 \mathrm{~g} / \mathrm{cm}^{3}$ para a densidade do embasamento. Os perfis modelados estão apresentados na figura 4 . O posicionamento do corpo em profundidade foi baseado em observações e trabalhos sobre a geologia de intrusões alcalinas (ex. Rosales 1999, Slavec 2000).

$O$ perfil XA apresenta uma descontinuidade na curva

Tabela 1 - Grupos litológicos considerados para modelagem.

\begin{tabular}{ccl}
\hline Grupo & $\begin{array}{c}\text { Densidade média } \\
\left(\mathrm{g} / \mathrm{cm}^{3}\right)\end{array}$ & \multicolumn{1}{c}{ Rocha } \\
\hline A & 2,50 & Fonolitos e Nefelina-sienitos \\
B & 2,54 & Fonolitos e Nefelina-sienitos \\
C & 2,47 & Fonolitos e intrusivas \\
D & 2,62 & Fonolitos \\
E & 2,46 & Arenitos \\
F & 2,33 & Siltitos \\
\hline
\end{tabular}

observada, na posição $52 \mathrm{~km}$, que indica o contato entre duas estruturas com diferentes densidades, o que implica na coincidência da informação gravimétrica com a definição dos grupos A e B. A inclusão de dois corpos com densidades correspondentes à amostra 8, coletada na região onde ocorre um granitóide do Complexo Varginha, faz com que a curva calculada se ajuste aos dados observados. Como a alcalina e os granitóides considerados não apresentam idades semelhantes, pode-se modelá-los separadamente, sem que exista uma conexão entre os dois.

No perfil XB, os contatos definidos pelo modelo também se apresentam compatíveis com os dados gravimétricos e com as observações em superfície. Nesse perfil pode ser observado um prolongamento do corpo na direção $\mathrm{N}$, além dos limites definidos pela geologia em superfície. Na porção $\mathrm{N}$ deste perfil, foi modelada uma camada com densidade menor daquela do embasamento, correspondendo a um grupo de amostras coletadas na região, o que permitiu ajustar as curvas calculada e observada.

$\mathrm{O}$ perfil XC apresenta uma descontinuidade mais suave na posição $50 \mathrm{~km}$, que também indica um contato entre duas litologias diferentes, concordando com a presença dos grupos A e B. Já o perfil XD apresenta uma quebra na posição de $40 \mathrm{~km}$, correspondendo à separação dos grupos A e B. No ponto correspondente ao cruzamento dos perfis analisados, observa-se a correlação entre as profundidades obtidas.

Para comparação, utilizou-se um algoritmo de modelagem 3D, desenvolvido por Murthy \& Swamy (1995), que utiliza um método de inversão não linear. O programa analisa a informação sobre a anomalia gravimétrica da região de interesse e, por processos iterativos, baseados em técnicas de otimização, estima valores para o contraste de densidade entre o maciço alcalino e o embasamento rochoso e para a profundidade do topo e da base do corpo. A modelagem 3D utilizada constitui um método independente, que não requer a entrada de dados de densidade das rochas ou da profundidade do corpo. A figura 5 apresenta um dos modelos possíveis, onde se observa que o polígono obtido

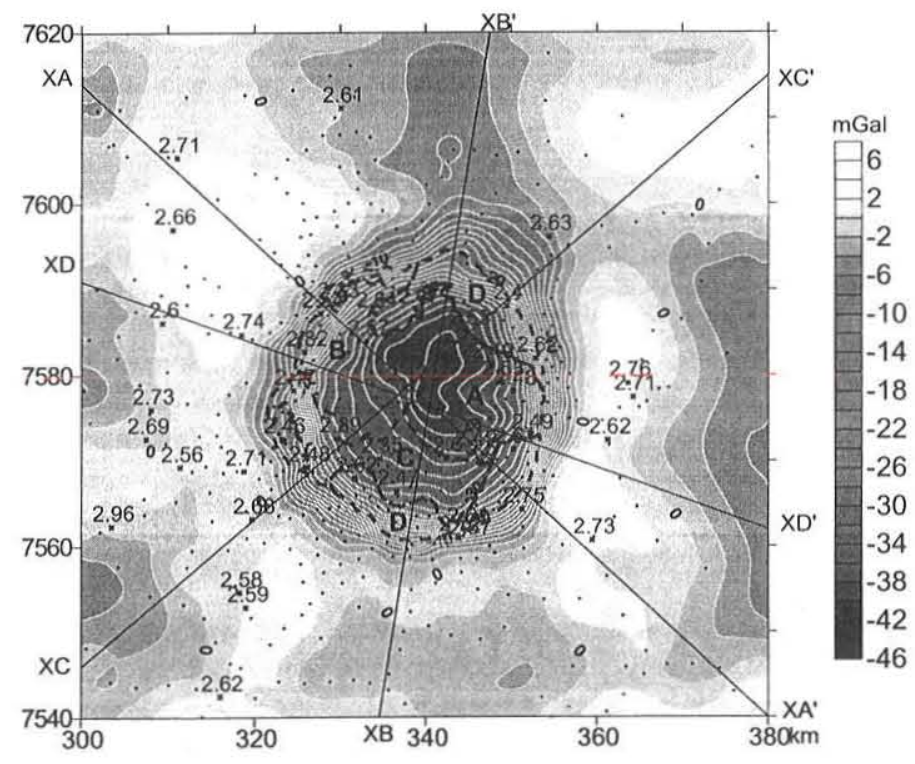

Figura 3 - Mapa residual Bouguer sobreposto ao mapa geológico simplificado (linha tracejada, grupos $A, B, C, D, E e$ $F)$ e dos perfis $X A, X B, X C$ e $X D$ 

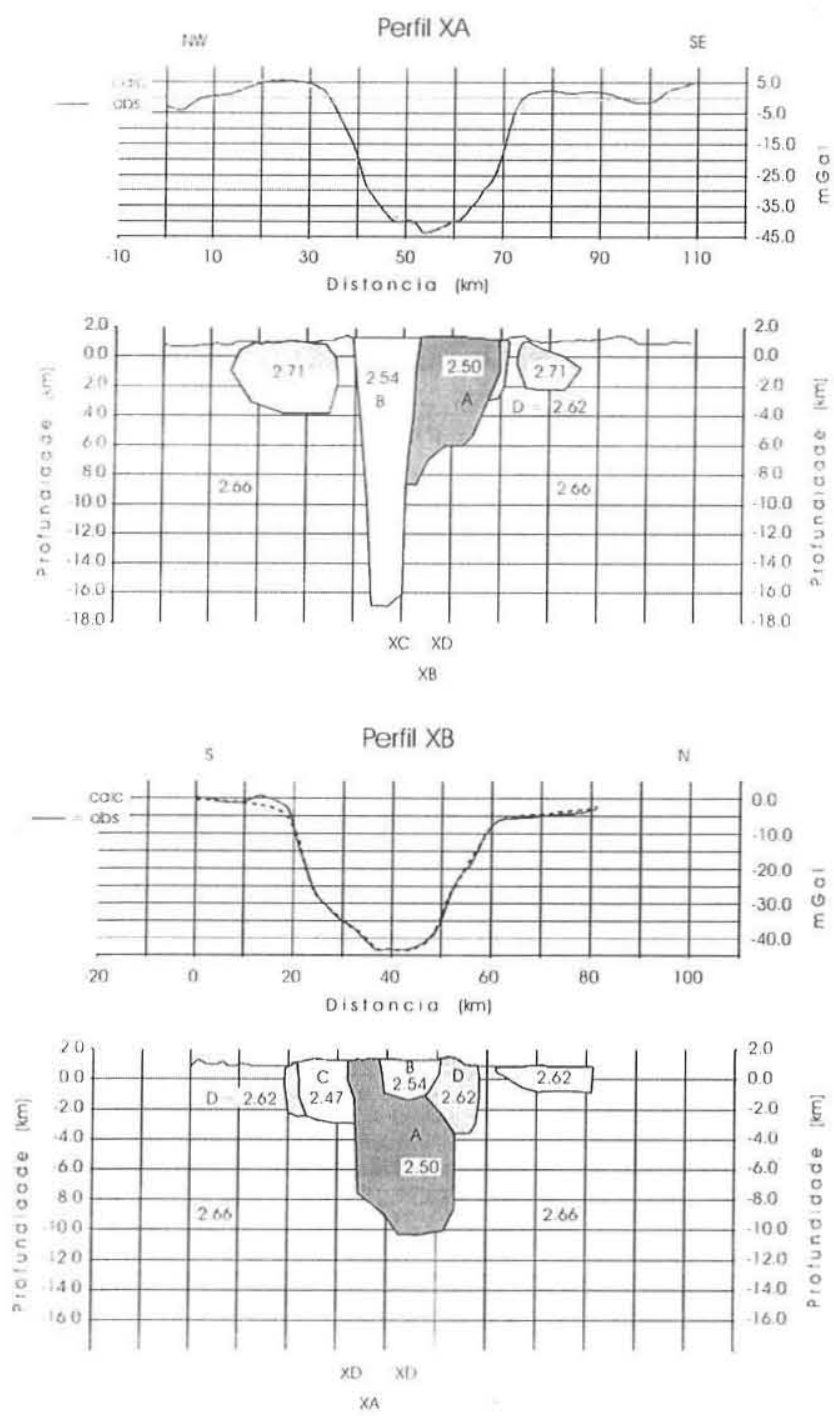

Figura 4 - Perfis modelados

tende a se ajustar à geologia aflorante em superfície, indicando que o modelo 3D discutido pode ser utilizado como uma boa estimativa para o caso do Maciço de Poços de Caldas.

O programa que utilizou o algoritmo de Murthy \& Swamy (1995) foi processado diversas vezes, alterando-se os parâmetros de entrada e o polígono inicial. O contraste de densidade obtido variou entre $-0,19$ até $0,17 \mathrm{~g} / \mathrm{cm}^{3}$, concordando com os dados utilizados para a modelagem 2,5 D. Da mesma forma, as profundidades obtidas concordam com as profundidades do modelo 2.5 D, que variam entre 7,0 e $9,0 \mathrm{~km}$, chegando até $17 \mathrm{~km}$ na sua raiz mais profunda.

A partir dos resultados obtidos dos perfis (Fig. 4), o mapa da figura 3 foi re-elaborado, considerando-se as variações dos limites de cada grupo nos perfis. O resultado, apresentado na figura 6 , mostra que a distribuição inicial se mantém, com algumas alterações, principalmente estendendo o maciço para além dos limites definidos pela geologia nas bordas NNE e para toda a região SW-S-SE.

A área do Maciço, definida por modelagem geofísica e estimada a partir da figura 6 , é de $920 \mathrm{~km}^{2}$, superior, portanto à estimativa
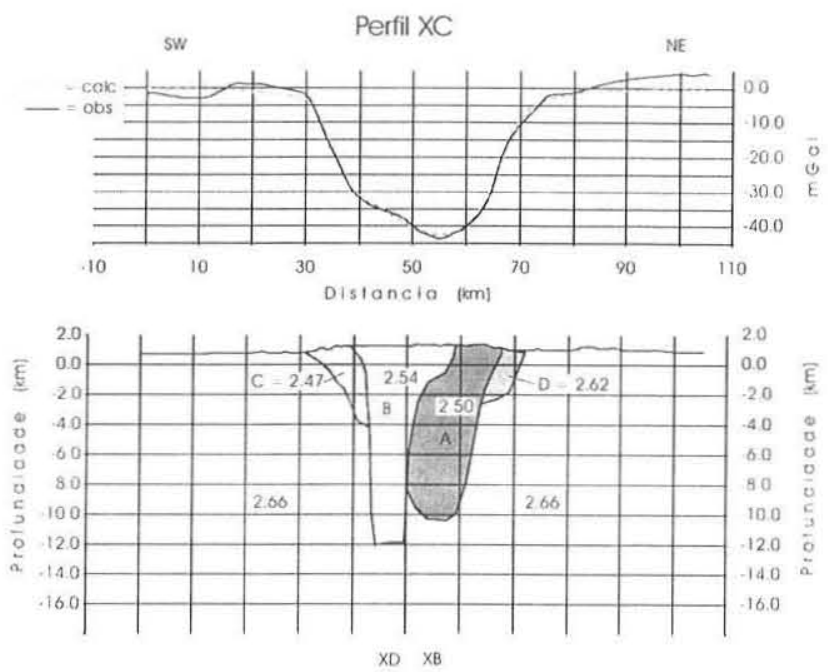

$X A$
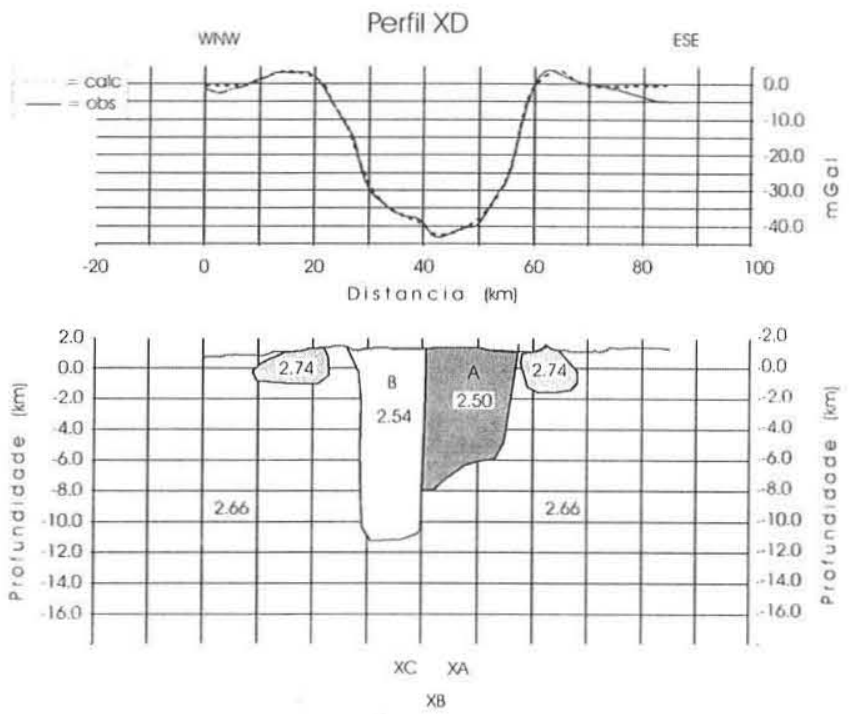

anterior de $800 \mathrm{~km}^{2}$ (Ulbrich 1992), feita por aproximação de um círculo de diâmetro igual a $32 \mathrm{~km}$. No entanto, essa diferença baseada em dados geofísicos implica numa continuidade em subsuperfície das estruturas aflorantes, definindo assim os limites geofísicos da extensão do maciço.

Considerando-se a área de $800 \mathrm{~km}^{2}$ e as estimativas de profundidade de 10 a 12 km, Ulbrich \& Ulbrich (1992) obtém um volume entre 8.000 e $9.600 \mathrm{~km}^{3}$ para o Maciço. Analisando os resultados geofísicos obtidos pelo modelo $3 \mathrm{D}$, com uma profundidade média de $7,35 \mathrm{~km}$, obtém-se um volume de $5.900 \mathrm{~km}^{3}$. Os resultados sugeridos pela modelagem $2,5 \mathrm{D}$, apresentam um volume de $7.220 \mathrm{~km}^{3}$, estando de acordo com o modelo de geometria 3D. Esses resultados mantêm a posição do Maciço Alcalino de Poços de Caldas entre as maiores intrusões־alcalinas conhecidas no mundo, sendo ultrapassado somente pela intrusão de Khibina, na Península de Kola, na Rússia (Arzamastsev et al.2001).

CONCLUSÕES Foi efetuado um levantamento gravimétrico de precisão na região do maciço alcalino de Poços de Caldas. A partir 

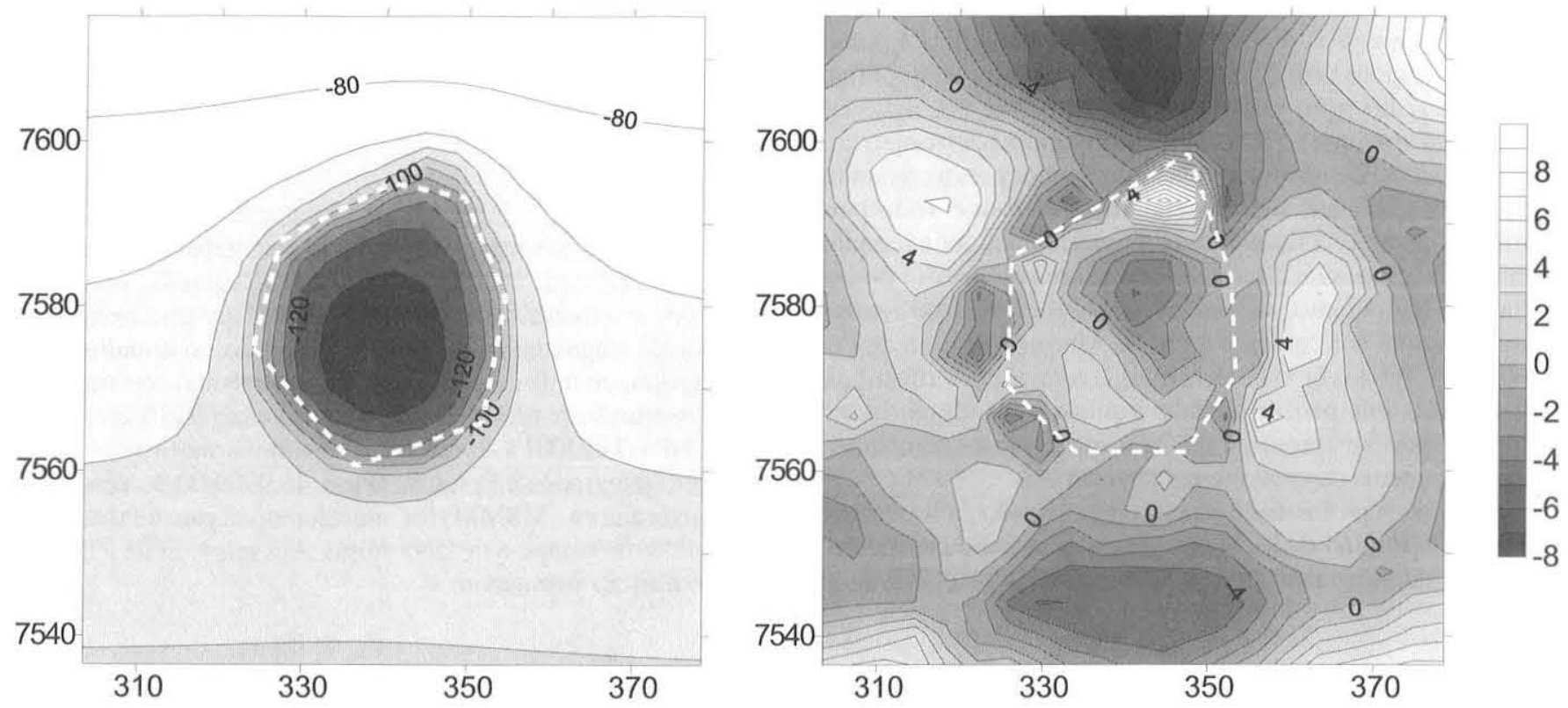

Figura 5 - À esquerda, o campo Bouguer calculado, juntamente com o polígono inicial, tracejado. À direita, o mapa de resíduo e o polígono obtido depois do processo iterativo, tracejado.

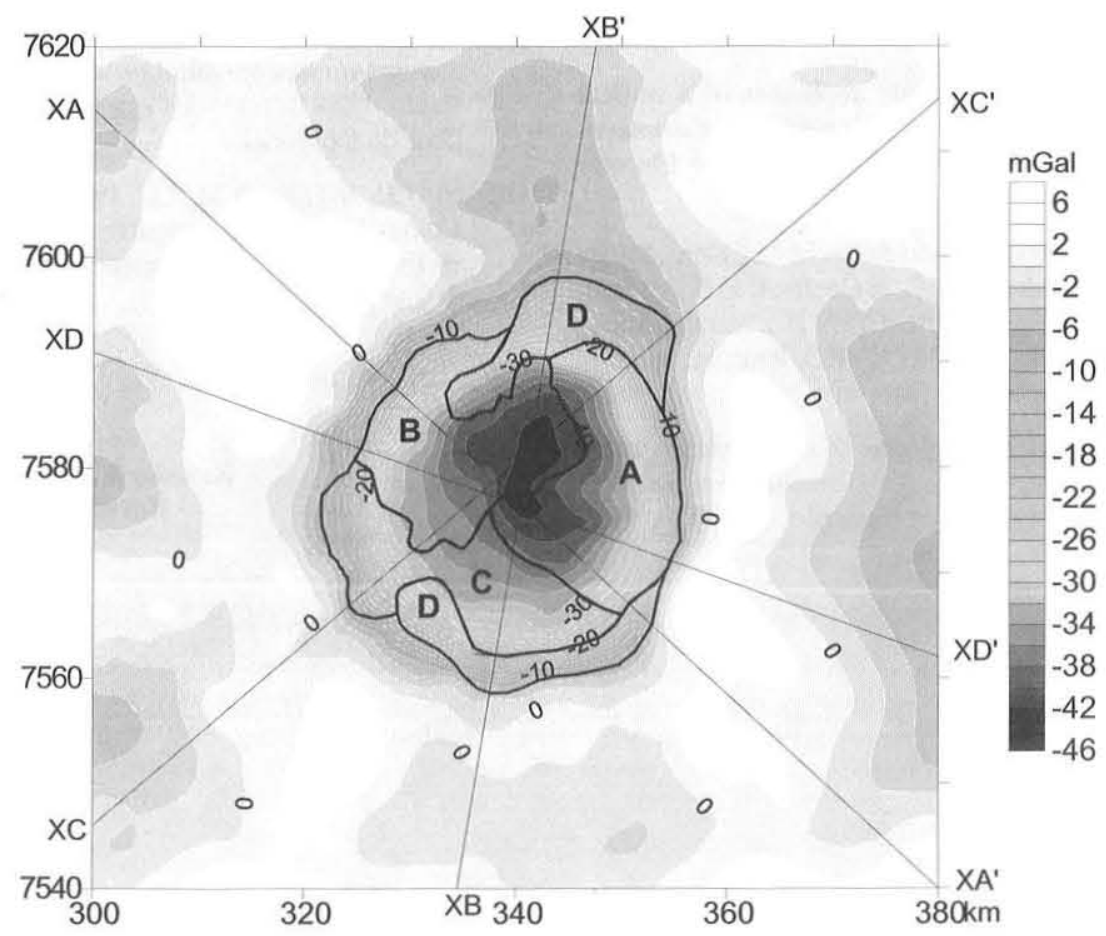

Figura 6 - Disposição dos grupos A', B', C'e D', de diferentes densidades, no interior do maciço após os estudos gravimétricos realizados.

dos dados de levantamentos anteriores e os obtidos durante o estudo, a Geofísica favorece o modelo de poucas efusões sucessivas, originando dois ou três grupos com diferentes propriedades físicas na região. Entretanto, tais intrusões não puderam ser situadas temporalmente, em vista da metodologia utilizada para as datações disponíveis. Para uma melhor definição da sucessão de eventos eruptivos, seria conveniente a realização de datações sistemáticas, utilizando o método $\mathrm{Ar} / \mathrm{Ar}$, atualmente disponível e amplamente utilizado para a faixa de idade do maciço analisado.

O número de amostras utilizadas neste trabalho foi pequeno 
se comparado à grande extensão da área de estudo. As dificuldades de acesso a algumas regiões e o tempo limitado para a pesquisa deixaram regiões sem dados, mas que poderiam ser importantes para a caracterização mais detalhada do corpo. Por motivos de segurança nacional, dados de aerogamaespectrometria, da Nuclebrás/CNEN, não foram disponibilizados para a comunidade acadêmica. Sua utilização teria sido de grande valia para o enriquecimento do presente trabalho definindo, por exemplo, os limites dos grupos de diferentes densidades no interior do corpo alcalino. No entanto, o levantamento gravimétrico realizado apresenta uma boa caracterização do Maciço Alcalino de Poços de Caldas,. Tendo como modelo mais favorável para a distribuição do maciço em profundidade aquele cuja densidade do embasamento se aproxima de $2,66 \mathrm{~g} / \mathrm{cm}^{3}$, valor semelhante à densidade média da crosta terrestre superior.

A raiz mais profunda do Maciço Alcalino não deve ultrapassar $17 \mathrm{~km}$ de profundidade, sendo que a profundidade média do Maciço resulta da ordem de 7,5 a $8,0 \mathrm{~km}$. O volume total da alcalina foi estimado em $7.220 \mathrm{~km}^{3}$ para uma área superficial de pouco mais que $800 \mathrm{~km}^{2}$, o que mantém o Maciço Alcalino de Poços de Caldas como o segundo maior maciço desse tipo conhecido na Terra, sendo ultrapassado apenas pela intrusão de Khibina, na Rússia, com $1500 \mathrm{~km}^{2}$.

Agradecimentos Ao Prof. Dr. Horstpeter Ulbrich (IGc/USP), pelas discussões, sugestões e interesse pelo trabalho. Aos técnicos e colegas Eduardo Moraes Leite e André Rugenski pelo apoio de campo e no laboratório de cálculo. À CPRM que gentilmente cedeu mapas de magnetometria da região de estudo, contribuindo para a integração de informações geofísicas.O trabalho constituiu tema de dissertação de mestrado da primeira autora (GdBS) com bolsa do $\mathrm{CNPq}$ (Jan/2001 a Ago/2002). O auxílio financeiro do CNPq, ao Projeto Integrado de Pesquisa (Proc. 46.9909/00-5 - concedido à segunda autora - MSMM) foi imprescindível para a execução dos trabalhos de campo e de laboratório. Aos relatores da RBG pelas sugestões ao manuscrito.

\section{Referências}

Arzamastsev' A.A., Bea ${ }^{2}$ F., Glaznev' V.N., Arzamastseva' L.V., Montero ${ }^{2}$ P.2001. Kola alkaline province in the Paleozoic: evaluation of primary mantle magma composition and magma generation conditions. Russian Journal of Earth Sciences, 3: 1 - www.agu.org/wps/rjes/ $\mathrm{v}(03 / \mathrm{tje} 01054 / \mathrm{tje}) 1(054 . \mathrm{htm}$

MurtHy I.V.R. \& Swamy,K.V. 1995. Gravity anomalies of a vertical cylinder of polygonal cross-section and their inversion. Computers \& Geosciences 22: 6, 625-630, 1996. Copyright 1996 Elsevier Science Ltd.

Parisi C.A. 1988. Jazidas de bauxita da região de Poços de Caldas, Minas Gerais - São Paulo. In Schobbenhaus C. \& Coelho C.E.S. - coords. - Principais depósitos minerciis do Brasil. (Vol III), metais básicos não-ferrosos, ouro e alumínio, DNPM / CVRD, Brasília, pg. 661666.

Rosales M.J.T. 1999. Caracterização geofísica do complexo intrusivo ultrabásico-alcalino de Jacupiranga, (SP). Instituto Astronômico e Geofísico, IAG/USP. Dissertação de mestrado, 120 pp.
Slavec G.B. 2000. Estudo Gravimétrico do Complexo alcalino de Juqiá$S P$. IAG/USP. Trabalho de Graduação II. 35 pp

Sørensen H. 1974. The alkaline rocks. John Wiley \& Sons, 622pp.

Ulbrich H.H. 1984. A petrografia, a estrutura e o quimismo de nefelina sienitos do maciço alcalino de Poģos de Caldas, $M G$ - SP. São Paulo, 480p. Instituto de Geociências da Universidade de São Paulo. Tese de Doutorado.

Ulbrich H.H. \& Ulbrich M.N.C. 1992. O Maciço alcalino de Poços de Caldas, MG - SP: Características Petrográficas e Estruturais. Roteiro de Excursão do $37^{\circ}$ Congresso Brasileiro de Geologia. SBG/SP. Vol. 5. São Paulo, SP, 1992.

Manuscrito A-1452

Recebido em 24 de julho de 2003

Revisão dos autores em 05de março de 2004 Revisão aceita em 15 de março de 2004 